\title{
ATOMIC-ABSORPTION DETERMINATION OF PALLADIUM IN COPPER ANODE SLIME AFTER SELECTIVE SEPARATION BY SYNERGISTIC EXTRACTION
}

\author{
LEE, GEUM-HEE and CHUNG, KOO-SOON \\ Department of Chemistry, Sogang University, C.P.O. Box 1142, Seoul 100-611, Korea
}

\begin{abstract}
A synergistic extraction system has been reported in a previous paper for the selective extraction of Pd from solution also containing Pt with quinolin-8-ol and tributylphosphite in $\mathrm{CHCl}_{3}[1]$. This method was applied to a synthetic sample solution, the composition of which was similar to that of anode slime obtained from an electrolytic copper refinery. The results indicated that trace amounts of approximately $5 \times 10^{-4} \mathrm{M}$ Pd could be separated from similar concentrations of Pt. Under the conditions employed, $\mathrm{Cu}$ was extracted only to a negligible extent. In the present work, the method was applied to a real sample of copper anode slime which had the following composition; Pd, 0.36; Pt, 0.27; Pb, 0.16; Ag, 0.075; $\mathrm{Cu}, 0.019 ; \mathrm{Rh}$, 0.013 and trace amounts of $\mathrm{Ir}$ and $\mathrm{Au}$ (total mass, $0.90 \mathrm{~g}$ ). The $\mathrm{Pd}$ in $\mathrm{CHCl}_{3}$ phase was found to be quantitatively back-extractable within 5 minutes by shaking with dilute $\mathrm{HCl}$ solution containing $0.5 \mathrm{M}$ thiourea. Details of the extraction procedure including the back-extraction process for the separation of Pd as well as the analytical results of $\mathrm{Pd}$ contents in sample, as determined by atomic-absorption spectrophotometry, are described in this paper.
\end{abstract}

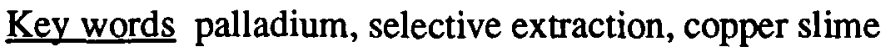

\section{INTRODUCTION}

In a previous paper we have reported a new method of synergistic extraction which has been developed for the selective separation of Pd from Pt[1]. The method was based on the extraction of Pd with chloroform containing 8-hydroxy quinoline (HQ) and tributylphosphite (TBPI). When a solution containing both $\mathrm{Pd}$ and $\mathrm{Pt}\left(5 \times 10^{-4} \mathrm{M}\right.$ each) was extracted using the proposed method, the separation of Pd from Pt was in the ratio of 2000:1. The proposed method was applied to a synthetic sample solution which contained various elements in amounts similar to those expected in solutions of anode slime obtained from an electolytic copper refinery. The mixture had the following composition : $\mathrm{Ag}, 0.076 ; \mathrm{Cu}, 0.19 ; \mathrm{Bi}, 0.076 ; \mathrm{Se}, 0.053 ; \mathrm{Zn}, 0.038 ; \mathrm{Pd}$, 0.053 ; $\mathrm{Pt}, 0.097$; and $\mathrm{Pb}, 0.18 \mathrm{~g}$ (total mass, $0.76 \mathrm{~g}$ ). The results also indicated that trace amounts of Pd (ca. $5 \times 10^{-4} \mathrm{M}$ ) could be separated effectively from equal amounts of $\mathrm{Pt}$.

In the present work, the proposed method was developed as a selective preconcentration method, which was applicable to a real sample of copper anode slime. The Pd in chloroform phase was found to be quantitatively back extractable within 5 minutes by shaking with dilute hydrochloric solution containing $0.5 \mathrm{M}$ thiourea. After back-extraction, the Pd in aqueous phase was determined by atomic absorption spectrophotometry. The separation of $\mathrm{Pd}$ from $\mathrm{Pt}$ and also from various coexisting elements contained in copper anode slime were found to be satisfactory. 


\section{EXPERIMENTAL}

Chemicals All the chemical reagents were prepared as described previously[1]. Prior to extraction the oxidation states of $\mathrm{Pd}(\mathrm{II})$ and $\mathrm{Pt}(\mathrm{IV})$ in $\mathrm{HCl}$ were confirmed by visible absorption spectra[2]. The solid sample of copper anode slime had the following composition; Pd, 0.36; Pt, $0.27 ; \mathrm{Pb}, 0.16 ; \mathrm{Ag}, 0.075 ; \mathrm{Cu}, 0.019 ; \mathrm{Rh}, 0.013 \mathrm{~g}$; trace amounts of Ir and Au (total mass, $0.90 \mathrm{~g})$. It was treated as follows:

Extraction, back-extraction and determination of Pd To a beaker containing the slime sample was added aqua regia and the solution was heated on a hot-plate to near-dryness. Concentrated $\mathrm{HCl}$ was then added and the contents of the beaker were evaporated to dryness; the treatment with concentrated $\mathrm{HCl}$ was repeated twice more after which the dry mass was dissolved in $5 \mathrm{x}$ $10^{-3} \mathrm{M} \mathrm{HCl}$ and the grey residue was filtered through two sheets of filter-paper (Whatman No.1). The concentrations of Pd and Pt were determined by atomic absorption spectrometry ( $339 \mathrm{~nm}$ for $\mathrm{Pd}, 265 \mathrm{~nm}$ for $\mathrm{Pt})$. A $10-\mathrm{mL}$ volume of the sample solution $\left(5 \times 10^{-3} \mathrm{M} \mathrm{HCl}\right.$ ) was extracted with an equal volume of $\mathrm{CHCl}_{3}$ containing $5 \times 10^{-4} \mathrm{M}$ HQ plus $1 \times 10^{-3} \mathrm{M}$ TBPI. The Pd in $\mathrm{CHCl}_{3}$ phase was back-extracted into aqueous phase by shaking with dilute $\mathrm{HCl}$ solution containing $0.5 \mathrm{M}$ thiourea. As expected, the results indicated that trace amounts of Pd (ca. $5 \mathrm{x}$ $10^{-4} \mathrm{M}$ ) could be determined quantitatively by atomic absorption spectrometry after effective separation that employed selective synergistic extraction as well as back-extraction using thiourea.

\section{RESULTS AND DISCUSSION}

Extraction The sample solution was extracted with $\mathrm{CHCl}_{3}$ containing HQ plus TBPI. The distribution coefficients of various elements contained in the anode slime were obtained as shown in Table 1. The metal concentration in the aqueous phase was determined by atomic absorption spectrometry, while the metal concentration in the organic phase was calculated from the difference between the metal content in the aqueous phase before and after extraction. The separation ratio is defined as $D(P d) / D(P t)$, where $D(P d)$ and $D(P t)$ are the distribution coefficients of each metal between the aqueous and organic phases.

TABLE 1. Distribution coefficients of various elements contained in anode slime

\begin{tabular}{llllllll}
\hline & \multicolumn{7}{c}{ Distribution coefficient } \\
\cline { 4 - 5 } Extractant & Pd & Pt & Cu & Rh & Ir & Au \\
& & & & & & \\
HQ $\left(5 \times 10^{-4} \mathrm{M}\right)$ & 0.545 & 0.016 & 0.11 & 0.22 & $<$ d.l. & $<$ d.l. \\
TBPI $\left(1 \times 10^{-3} \mathrm{M}\right)$ & 1.43 & 0.055 & 0.098 & 0.10 & $<$ d.l. & $<$ d.l. \\
HQ + TBPI & 40.1 & 0.041 & 0.11 & 0.079 & $<$ d.l. & $<$ d.l. \\
$\left(5 \times 10^{-4} \mathrm{M}\right)\left(1 \times 10^{-3} \mathrm{M}\right)$ & & & & & & \\
\hline
\end{tabular}

d.l. = detection limit

Back-extraction of Pd with thiourea A 10-mL volume of chloroform containing Pd (ca. $5 \times 10^{-4}$ $\mathrm{M}$ ), which had been previously extracted into $\mathrm{CHCl}_{3}$ phase with $5 \times 10^{-4} \mathrm{M}$ HQ plus $1 \times 10^{-3}$ TBPI, was back-extracted by shaking with an equal volume of $\mathrm{HCl}$ solution containing various concentrations of thiourea. The back-extraction efficiencies of Pd are shown in Table 2. 
TABLE 2 Back-extraction efficiencies of $\mathrm{Pd}$ from $\mathrm{CHCl}_{3}$ phase into aqueous phase with thiourea. Shaking time $=15 \mathrm{~min}$. Shaking speed $=120$ r.p.m.

\begin{tabular}{lc}
\hline \multicolumn{1}{c}{ Back-extractant } & Recovery ratio of Pd \\
\cline { 2 - 2 } $2.0 \mathrm{M} \mathrm{HCl}$ containing 0.2 M thiourea & $81 \%$ \\
$1.0 \mathrm{M} \mathrm{HCl}$ containing 0.2 M thiourea & $90 \%$ \\
$0.5 \mathrm{M} \mathrm{HCl}$ containing 0.2 M thiourea & $97 \%$ \\
& \\
$0.5 \mathrm{M} \mathrm{HCl}$ containing 0.1 M thiourea & $67 \%$ \\
$0.5 \mathrm{M} \mathrm{HCl}$ containing 0.2 M thiourea & $97 \%$ \\
$0.5 \mathrm{M} \mathrm{HCl}$ containing 0.5 M thiourea & $100 \%$ \\
\hline
\end{tabular}

As shown in Table 2, trace amounts of Pd (ca. $5 \times 10^{-4} \mathrm{M}$ ) in $\mathrm{CHCl}_{3}$ phase could be quantitatively back- extracted into the aqueous phase by shaking with $0.5 \mathrm{M} \mathrm{HCl}$ containing 0.5 $M$ thiourea within $15 \mathrm{~min}$. In order to minimize the shaking time, further extractions were made, which indicated that $5 \mathrm{~min}$. shaking was adequate for back-extraction of Pd as shown in Table 3.

TABLE 3. Back-extraction efficiencies of Pd at various shaking times. Back-extractant $=0.5 \mathrm{M} \mathrm{HCl}$ containing $0.5 \mathrm{M}$ thiourea. Shaking speed $=120$ r.p.m.

\begin{tabular}{lrrrrr}
\hline Shaking time $(\mathrm{min}):$ & 1 & 2 & 3 & 4 & 5 \\
Recovery ratio of Pd (\%): & 81 & 87 & 95 & 97 & 100 \\
\hline
\end{tabular}

The back-extraction of $\mathrm{Pd}$ by shaking with $0.5 \mathrm{M} \mathrm{HCl}$ containing $0.5 \mathrm{M}$ thiourea for $5 \mathrm{~min}$. is seen to be satisfactory. The quantitative recovery of Pd by the proposed back-extraction method was further confirmed in the case of a real sample of copper anode slime, as follows: The slime sample was treated with aqua regia and concentrated $\mathrm{HCl}$ as described above. The concentration of Pd in the filtrate, obtained as above, was determined by the ICP-AES method. An aliquot of the filtrate was extracted with $\mathrm{CHCl}_{3}$ containing $\mathrm{HQ}$ plus TBPI. The Pd extracted into $\mathrm{CHCl}_{3}$ phase was back-extracted by the proposed method with thiourea. After back-extraction, the Pd in aqueous phase was determined by atomic absorption spectrometry. The Pd concentration in the solution of slime sample as determined by the ICP-AES agreed well with that determined by atomic absorption spectrometry after back-extraction. This indicates the quantitative recovery of Pd by the proposed method of back-extraction.

In the initial stage of the present work, back-extraction of Pd was attempted using various methods which included $\mathrm{pH}$ variation of aqueous phase, shaking with concentrated acids or bases etc., however, none of them showed quantitative recovery of Pd. Thiourea is widely used in analytical chemistry, in particular solvent extraction of the platinum group metals[3,4]. Accordingly, thiourea was tried specifically for the back-extraction of Pd for the present work. Fortunately the results showed excellent recovery.

Pd complexes after back-extraction with thiourea In order to study the nature of the Pd complex formed in the back-extraction, a spectrophotometric absorption spectrum was obtained following the method described by Shlenskaya et al[3]. A portion of aqueous solution containing Pd was extracted with $\mathrm{CHCl}_{3}$ containing $\mathrm{HQ}$ plus TBPI, after which the $\mathrm{CHCl}_{3}$ phase was shaken with 
$\mathrm{HCl}$ containing various concentration of thiourea, as described above. The absorption spectra of the aqueous phase were recorded as shown in Fig. 1, which agrees well with the similar spectra reported previously[3].

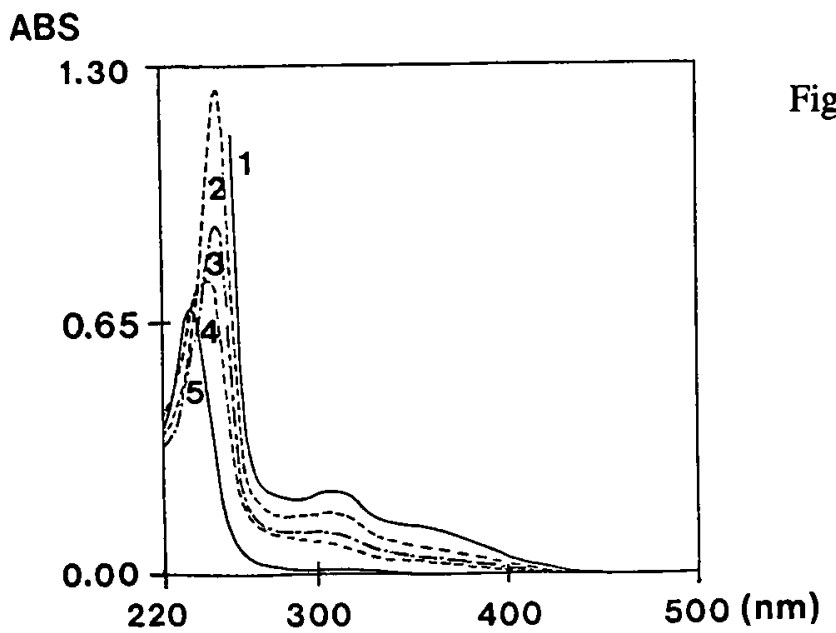

Fig. 1. Absorption spectra of thiourea complexes of $\mathrm{Pd}(\mathrm{II})$ in chloride media obtained after back-extraction with thiourea. $\mathrm{Pd}$ (II) concentration in $\mathrm{CHCl}_{3}$ phase $=$ ca. $5 \times 10^{-4} \mathrm{M}$. Back-extraction systems : [Thm]/[Pd(II)] : 1) $1: 1,2$ ) 2:1, 3) 3:1, 4) 5:1, 5) 1,000:1. After back-extraction, aqueous phase was diluted with $0.5 \mathrm{M} \mathrm{HCl}$ to the following ratio, respectively : 1) $1: 10$, 2) $1: 20$, 3) $1: 30$, 4) $1: 50,5) 1: 10,000$.

They showed that Pd formed the mixed complexes with thiourea in chloride media in the following manner, indicating gradual replacement of chloride ions by thiourea(Thm).

$$
\mathrm{PdCl}_{4}{ }^{2-}+\mathrm{n}(\mathrm{Thm}) \rightleftharpoons \mathrm{PdCl}_{4-\mathrm{n}}(\mathrm{Thm})_{\mathrm{n}}{ }^{2-\mathrm{n}}+\mathrm{nCl}^{-}
$$

In our previous work, in an attempt to investigate the composition of the extracted species via NMR spectroscopy and thermogravimetry, the species was postulated to be $\mathrm{Pd} \cdot \mathrm{Q} \cdot \mathrm{TBPI} \cdot \mathrm{Cl}[1]$. It is certainly noteworthy that judging from the similarity of two absorption spectra, the Pd species formed in the back-extraction by the present method now appear to be the mixed complexes of $\mathrm{PdCl}_{4-\mathrm{n}}(\mathrm{Thm})_{\mathrm{n}}{ }^{2-\mathrm{n}}$ as shown by Shlenskaya [3].

Further work The proposed method is currently being applied in our Laboratory in order to determine Pd in various samples of copper anode slime, and the results will be published elsewhere.

\section{ACKNOWLEDGEMENTS}

Financial support for the present work from the Korea Science and Engineering Foundation is gratefully acknowledged. We feel most grateful to the Research Center, Lucky Metals Cooperation who kindly determined our samples by the ICP-AES method.

\section{REFERENCES}

1. G. H. Lee and K. S. Chung, Analyst, 115 , 965 (1990).

2. U. V. Rao, "Platinum Group Metals and Compounds", Advances in Chemistry Series 98, American Chemical Society, Washington, D.C., 1971, p.75.

3. V. I. Shlenskaya, A. A. Biryukov and E. M. Moskovkina, Russ. J. Inorganic Chem., 11, 325 (1966).

4, Yu. A. Zolotov, O. M. Petrukhin, V. N. Shevchenko, V. V. Dunina and E. G. Rukhadze, Anal. Chim. Acta, 100, 613 (1978). 